\title{
ОТРАЖЕНИЕ РЕГИОНАЛЬНОЙ \\ САМОИДЕНТИФИКАЦИИ В РЕЧЕВОМ ПОВЕДЕНИИ ИНДИВИДУАЛЬНОЙ ЯЗЫКОВОЙ ЛИЧНОСТИ - ЖИТЕЛЯ СИБИРСКОЙ ПРОВИНЦИИ
}

\author{
Славкина И.А., Шмульская Л.С., Мамаева С.В., \\ Веккессер М.В.
}

Предметом исследования явились способы отражения и лингвистического выражения региональной самоидентификации в речевом поведении отдельной языковой личности.

Материалом исследования послужили записи текстов интервью с жительницей сибирской провинции; текстов бесед с бывшими односельчанами; протоколь наблюдения за речевым поведением информанта.

Цель. Выявить маркеры региональной самоидентификации в речевом поведении индивидуальной языковой личности.

Методы исследования: описательный метод и метод контекстуального анализа.

Результаты. Региональная идентичность определяется как форма коллективной идентичности, при которой ее носитель оказывается способным к пространственно-временной идентификации, иенностному, эмоциональному, регулятивному соотнесению с внешним миром. При анализе текстов бесед, интервьюирования выявлены определённые черты, отражающие региональную «самость».

Ключевые слова: региональная самоидентификация; индивидуальная языковая личность; маркеры региональной самоидентификации. 


\section{REFLECTION OF REGIONAL SELF-IDENTIFICATION IN THE SPEECH BEHAVIOUR OF THE INDIVIDUAL LINGUISTIC PERSONALITY - THE RESIDENT OF THE SIBERIAN PROVINCE}

\section{Slavkina I.A., Shmulskaya L.S., Mamayeva S.V., Vekkesser M.V.}

The ways of reflecting and linguistic expression of regional self-identification in the speech behavior of a particular linguistic personality are the subject of the study. The research is based on the recording of the texts of the interview with a resident of the Siberian province; the texts of the conversations with former villagers; the monitoring protocols of the informant's speech behavior.

Goal. To identify the markers of regional self-identification in the speech behavior of the individual linguistic personality.

Research methods: the descriptive method and the method of the contextual analysis.

Results. The regional identity is defined as a form of collective identity at which its carrier is capable of spatiotemporal identification, valuable, emotional, regulatory correlation with the outside world. Upon analyzing the texts of the interviews and conversations, certain features that reflect the regional "self" have been revealed.

Keywords: regional self-identification; individual linguistic personality; markers of regional self-identification.

Языковая личность - одно из центральных понятий современной лингвистики, что соответствует антропоцентрической направленности современного языкознания (А.А. Леонтьев, Ю.Н. Караулов и др.). По определению Ю.Н. Караулова, языковая личность - это человек, обладающий способностью создавать и воспринимать тексты, различающиеся: 1) степенью структурно-языковой сложности; 2) глубиной и точностью отражения действительности; 3 ) определенной целевой направленностью [8, с. 15]. 
Термин «языковая личность» впервые был употреблен В.В. Виноградовым в книге «О языке художественной прозы». Свое дальнейшее развитие понятие «языковая личность» получило в исследованиях Л.П. Крысина (1994), Ю.С. Караулова (1997), В.И. Карасика (2003, 2004), Н.Л. Красавского (2008), (1994), Т.В. Романовой (2009), Т.П. Тарасенко (2007) и многих других. Однако до сих пор не существует единства мнений в определении понятия «языковая личность», четко не определены методы и способы ее описания.

Ю.Н. Караулов представил лингво-когнитивную структуру языковой личности. В качестве составляющих языковой способности автор выделяет:

- вербально-семантический (или вербально-грамматический, или ассоциативно-вербальный) уровень, предполагающий владение естественным языком;

- когнитивный уровень, основывающийся на когнитивной деятельности языковой личности, в результате которой человек приходит к определенному решению или знанию. Знание это не собрание случайных фактов, а набор сведений, объединенных в определенную упорядоченную систему;

- прагматический уровень, проявляющийся в способности построить сообщение, выразить свое отношение к сообщаемому, к участникам коммуникативной ситуации, а также обозначить свою роль в ней, выразить свое «я» [8, с. 53].

В.В. Красных, характеризуя языковую личность, говорит о ней как о совокупности трех «личностных» феноменов: человек говорящий - личность, одним из видов деятельности которой является речевая деятельность, охватывающая как порождение, так и восприятие речевых произведений; языковая личность - как личность, проявляющая себя в речевой деятельности, обладающая определенной совокупностью знаний и представлений; речевая личность как личность, реализующая себя в коммуникации, выбирающая и осуществляющая ту или иную стратегию и тактику общения, выбирающая и использующая тот или иной репертуар средств (как собственно-лингвистических, так и экстралингвистических) [10, с. 22]. 
Понятие «языковая личность» предполагает рассмотрение каждого носителя языка в качестве уникального объекта изучения. Однако в сходных, или в однотипных, коммуникативных ситуациях люди ведут себя одинаково. Это связано с тем, что говорящие в своем индивидуальном речевом поведении демонстрируют общие особенности группового речевого поведения: отдельный носитель языка «как бы фокусирует в себе черты коллективных языковых личностей» [4, с. 114]. Например, житель города одновременно может выступать как языковая личность горожанина, языковая личность студента-словесника, как гендерная языковая личность и т.д.

Таким образом, возможно выделение совокупной языковой личности, которая отражает типичные черты речевого поведения определенного языкового коллектива (русская языковая личность, языковая личность школьника, сельского жителя и т.д.), и индивидуальной языковой личности (идиолектная языковая личность). Языковая личность как совокупный объект и как конкретный носитель данного языка не существуют друг без друга и представлены как две стороны одной медали. Как справедливо отмечает В.С. Юрченко, «абстрактный говорящий репрезентируется через конкретного говорящего, но тождества между ними нет, как нет тождества между сущностью и явлением, языком и речью» [19, с. 5].

Предметом рассмотрения данной статьи выступает речевое поведение индивидуальной языковой личности как один из способов отражения региональной самоидентификации. Респондентом явилась уроженка Мотыгинского района Мария Николаевна И., родившаяся в с. Денисово Мотыгинского р-на Красноярского края в 1936 г. Родители Марии Николаевны, старшие сестры и братья были раскулачены и высланы из центральной России в Сибирь. С 1957 г. Мария Николаевна работала учителем начальных классов в школе п. Первомайск Мотыгинского р-на. Речевое поведение избранной языковой личности представляет определенный научный интерес в аспекте проблемы отражения региональной самоидентификации, поскольку Мария Николаевна в силу профессиональной деятельности является носителем литературного языка, и в то же время в ее речи активно проявляются диалектные и региональные элементы. 
Региональная самоидентичность отражает изменения в понимании индивидами себя, своего места в мире и многообразие процессов глобализации или локализации и их культурных, политических, экономических эффектов. А.А. Анисимова, О.Г. Ечевская называют территориальную (региональную) идентичность «культурным феноменом, отражающим взаимодействие глобальных тенденций или локальных откликов на них; биографическим проектом (результатом не только переосмысления территории и ее границ, но и способа взаимодействия с территорией, истории проживания индивида на территории и за ее пределами); политическим проектом (в широком смысле слова), поскольку представляет собой один из видов «новой солидарности», способ публичного заявления общности о себе с целью признания отличий, культурной специфичности, социальных и экономических прав» [1, с. 43].

Вопросы самоидентификации жителей Приенисейской Сибири рассмотрены в ряде работ. Так, описаны особенности языковой картины мира сибиряков [2; 17], охарактеризованы специфические черты литературы и фольклора региона [3; 5; 12], выявлены маркеры региональной самоидентификации $[13 ; 15 ; 18]$. Вместе с тем проблема самоидентификации отдельной языковой личности не получила в научной литературе должного освещения. Хотя стоит признать, что в языковой личности проявляются и психические, и социальные, и этнические, и региональные особенности, но преломленные через ее язык, дискурс.

Изучение процесса территориальной самоидентификации языковой личности возможно через анализ речевого поведения. Материалом исследования послужили записи текстов интервью с Марией Николаевной И.; текстов ее бесед с бывшими односельчанами; протоколы наблюдения за речевым поведением информанта.

Анализ записи интервью с Марией Николаевной позволяет сделать вывод, что в ее картине мира «сибиряк» отличается от жителей других территорий: «Сибиряк ведь он крепкий, здоровый, честный, порядочный, самостоятельныймужик, умеет рыбу добыть и медведя убить. В лесу выжить. Всегда в моде и почете. Их всегда в войну в разведывательные отряды брали, они ведь честные, крепкие, 
порядочнье. Этим и отличаются от других: порядочностью, силой, деловыми качествами». Примечательно, что вопрос звучал «Кто такой сибиряк?». Информант же скорее отвечал на вопрос «Сибиряк, какой он?», перечисляя типичные, стереотипные представления о жителях Сибири. Указанные характеристики соотносятся со многими составляющими обобщенного образа русского мужика, богатыря.

Отмечая отличия жителей Мотыгинского р-на от других сибиряков, Мария Николаевна обращала внимание в большей степени на речевые особенности населения соседних территорий: «Рыбинщьы, мотыстниы, денисовские - у нас свои разговоры: чо, пошто, да зачем, да куды тыл. Были у нас свои поговорки и присказки: не отпадет голова - прирастет борода; отдО́хнем, когда сдохнем; по колено в навозе - по локоть в масле. В окружности так все разговаривали. А кежемщь, богучанџы - те смешно разговаривали, тянули. Я в Енисейске училась с ними, так когда они отвечали, смешно было. А потом год прошел, и ничего, научились говорить. А сначала заходят и спрашивают: люминева каштрюля эш (алюминиевая кастрюля есть?)... Тоже сибиряки, рыбаки, грибники, рыљсики лопатами брали. А у насто грибов не так было, как у них». Как видим, ни поведенческих, ни личностных отличий информантом названо не было, более того она указывает на то, что жители соседних территорий тоже сибиряки. Однако употребление в ее речи местоимений позволяет утверждать, что она неосознанно относит сибиряков из других районов к разным полюсам дихотомии «свой - чужой». Ср.: «mе смешно разговаривали», «у них свои поговорки»; «у нас свои разговоры»; «у нас грибов не так было». Неосознанно «свое» изначально воспринимается как лучшее и правильное. Ср.: «через год научились разговаривать».

В ходе беседы мы задали вопрос «Чем же хорош Мотыгинский район? Посоветовали бы вы жить в Мотыгинском районе?». Анализируя ответ информанта, стоит отметить, что социальные факторы, факторы материального благополучия оказываются абсолютно не значимы для нее (хотя в настоящее время Мотыгинский район испытывает известные трудности, свойственные малым провинциальным территориям). Важными для Марии Николаевны оказываются 
порядочные, хозяйственные, приветливые люди и удивительная природа: «Езжайте. Живите. Тут красивая река Ангара, чистая, прозрачная. Народ приветливый, всем поделится, встретит хорочо, хозяйственный, смекалистый, хваткий, бесхитростный... Bот похвастаюсь вам. Мне Клавдия Дмитриевна звонит, она кежемская, и говорит: «Вы, мотыгинские, так отличаетесь, вы такие деловые, смекалистые. А мы разявые, такой хватки нет». A то! Mь же столько рек перепльвали, по волнам ныряли. Вот и смелье, отчаянные люди!». Подобные рассуждения позволяют заключить, что в представлении данной языковой личности качества жителей того или иного региона во многом определяются природными условиями.

На наш взгляд, представляет интерес ответ Марии Николаевны на вопрос «Что такое для вас Родина?». В картине мира Марии Николаевны понятие «родина» - это не только территория, где родился и вырос, но и определенный период жизни - детство: «Родинаэто место, где родился, вырос, твоя земля, родители... Я выросла в этой деревне (Денисово). Подруга, она в Красноярске жсила, умерла уже, вот как жизнь сложслась...позвонит, бывало, и начнем с ней: вот бы встретиться, все тропинки наши пройти, на кладбищуе сходили бы, в Ангаре искупались... Помню, как рыбачили, как карасей ловили, как я до горя червей боялась... Цветьл, незабудки, это все такое родное.... Этот луг как зацветет жсарками и незабудками .... Отчий дом... Расскажу сейчас историю. Помню, Людмила Андреевна вызвала к доске Гошу Бакулина и спросила: "Какая столица нашей Родинь??», он думал, думал, а потом ответил: «Рыбная» (смеется) (прим. авт.: с. Рыбное Мотыгинского р-на). A то и была наша столицуа. У нас же там почта была...». Таким образом, родина в представлении анализируемой языковой личности предстает как нечто идеальное, наполненное яркими воспоминаниями. Интересно, что в данном случае отсутствуют признаки национальной самоидентификации, но явно представлены элементы локальной, «местечковой» самоотнесенности [18].

Записи бесед с бывшим односельчанами позволяют заключить, что Мария Николаевна охотно поддерживает темы, касающиеся про- 
шлого и настоящего Мотыгинского р-на. Одним из маркеров локализации пространства, проявляющемся в ее речи, можно считать использование таких лексических единиц, как здесь, эти, этот, переводящих объекты, события из разряда общих в разряд частных, наблюдаемых одновременно как автором, так и слушателем. Примечательно, что в настоящее время Мария Николаевна проживает в г. Лесосибирске, однако в своем повествовании относительно Мотыгинского р-на использует определенные лексико-грамматические показатели, отражающие ее сопричастность к родному селу: тут, здесь, у нас: "Поселок в 1954 году построился, но здесь даже в войну было несколько домишек»; "Ссыльных в поселке унас было много. Артистка была, пьесы с нами ставила. Дождя нет, а она с зонтиком ходила, от солнца закрывалась»; "Красные пришли 믄 нашу Рыбинскую». Используя разновидность местоименных слов, языковая личность мыслит и чувствует себя частью территориальной (локальной, региональной) и духовной общности.

Обращает на себя внимание включение в повествование различных типов онимов: антропонимов («Красные пришли, командиром у них Нил был»; «Артистка нами, Козыра, фамиль у нее такая, как мама моя говорила, дом на берегу построили. Валя ее знает»), гидронимов (Енисей, Ангара, Тасей, Удерей), эргонимов (Тасеевская сплавная контора, Слюдрудник, Машуковский леспромхоз, колхоз «Восток», колхоз "Спартак», совхоз «Чистяки», совхоз «Решающий»), дромонимов (Кондаковский тракт, Тасеевский тракт, Денисовская дорога, Пашина дорога, Медвежья тропа), агроонимов (Четверковские покосы, Кондаковские покосы), оронимов (скала Скородум, Гребень), ойконимов (поселки Первомайск, Рыбное, Денисово, Покукуй, Погорюй, Потоскуй, Зайцево, др.). Вышеуказанные онимы можно обозначить как единицы региональной прецедентности, т.е. значимые для языковой личности в когнитивном и эмоциональном отношении, отражающие общие, фоновые знания, объединяющие представителей региона. Подобные онимы могут рассматриваться как отражение регионального сознания говорящего, в данном случае можно говорить о региональной прецедентности 
как об одном из устойчивых способов выражения ключевых слов смыслового поля региональности, территориальности. Проявлением подобной региональной прецедентности можно считать диалектную лексику: «По весне такая растатуиха у нас»; «Занесла с веранды мясо, лежит три часа, конечно, забыгало»; «Может, сделал бы по-другому, да-к тяму не хватает». Диалектной особенностью грамматического характера можно считать особенности склонения имен собственных: «Он родом из Мотыгиной» (поселок Мотьгино); «Уедет в свою Денисову» (поселок Денисово).

Наблюдая за речевым поведением информанта, возможно отметить, что повествование о Мотыгинском р-не сопровождается указательными жестами, отражающими принадлежность к чему-либо или, напротив, некую дистанцированность.

Анализ речевых особенностей отдельной языковой личности позволяет заметить, что понимание своего места в мире, оценка пространственной общности проявляются как на вербальном, так и на невербальном уровнях. Наиболее частотными и показательными в аспекте самоидентификации языковой личности являются употребление диалектной лексики, включение в текст высказывания лексических единиц региональной прецедентности, использование лично-притяжательных местоименных слов. Обращаясь к указанным лингвистическим средствам, языковая личность осознанно или неосознанно мыслит и чувствует себя частью региональной (локальной) и социокультурной общности.

Таким образом, речевое поведение отдельной языковой личности репрезентирует особенности ее региональной самоидентификации как на вербально-семантическом, так и на когнитивном и прагматическом уровнях.

Исследование выполнено при финансовой поддержке Российского фонда фундаментальных исследований, Правительства Красноярского края, Красноярского краевого фонда поддержки научной и научно-технической деятельности в рамках научного проекта №16-14-24005. 


\section{Список литературы}

1. Анисимова А.А., Ечевская О.Г. Сибирская идентичность: предпосылки формирования, контексты актуализации: Монография. Новосибирск: НГУ, 2012. 176 с.

2. Бахор Т.А., Зырянова О.Н., Лобарева В.С. Ассоциативные поля как воплощение региональной самоидентификации // Инновационные технологии научного развития: сборник статей международной научно-практической конференции. Уфа, 2016 г. С. 83-84.

3. Веккессер М.В., Мамаева С.В., Славкина И.А., Шмульская Л.С. Проявление региональной самоиндетификации автора в поэтическом дискурсе // Современные исследования социальных проблем. 2016, № 3-2 (27). С. 120-134.

4. Горелов И.Н., Седов К.Ф. Основы психолингвистики. М.: «Лабиринт», 1998. $114 \mathrm{c}$.

5. Зырянова О.Н., Бахор Т.А., Лобарева В.С. Архетипическая основа малой прозы И. Пантелеева // Фундаментальные исследования. 2013, № 8-6. С. 487-490.

6. Карасик В.И. Аспекты языковой личности // Проблемы речевой коммуникации. Саратов, 2003. С. 96-106.

7. Карасик В.И. Языковой круг: личность, концепты, дискурс. М.: Гнозис, 2004. 390 с.

8. Караулов Ю.Н. Русский язык и языковая личность. М.: Наука, 1987. $262 \mathrm{c}$.

9. Красавский Н.Л. Эмоциональные концепты в немецкой и русской лингвокультурах: монография. М.: Гнозис, 2008. 374 с.

10.Красных В.В. Основы психолингвистики теории коммуникации: курс лекций. М.: ИТДГК «Гнозис», 2001. 270 с.

11. Крысин Л.П. Современный русский интеллигент: штрихи к речевому портрету // Литературный язык и культурная традиция. М.: РАН, Институт языкознания, 1994. 274. с

12. Мазурова Н.А., Зырянова О.Н., Бахор Т.А. Дендрологические образы как форма проявления региональной идентичности в творчестве поэтов Красноярского края // Современные исследования социальных проблем. 2016, № 3-2 (27). С. 195-207. 
13. Мамаева С.В., Славкина И.А., Шмульская Л.С., Веккессер М.В. Социолингвистический портрет школьников-подростков как речевой маркер региональной идентичности // Успехи современной науки. 2016, №9, том 4. С. 47-50.

14. Романова Т.В. Социо- и психолингвистические основания для типологической характеристики русской языковой личности // Социальные варианты языка: материалы междунар.науч.конф. (16-17 апр. 2009 г.). Н. Новгород, 2009. С. 24-27.

15. Славкина И.А., Шмульская Л.С., Мамаева С.В., Веккессер М.В. Вербальные маркеры региональной идентичности (на материале современных чоконимов) // Современные исследования социальных проблем. 2016, № 3-2 (27). С. 227-243.

16.Тарасенко Т.П. Языковая личность старшеклассника в аспекте ее реализации: Автореф. дис. ... канд. филол. наук. Краснодар, 2007. $25 \mathrm{c}$.

17. Фельде О.В. Образ Америки в языковом сознании жителей Средней Сибири (по данным психолингвистического эксперимента) // HOMO COMMUNICANS: Человек в пространстве межкультурных коммуникаций: коллективная монография / Под ред. Кристины Янашек, Йоланты Митурска-Бояновской. Щецин, GRAFFORM, 2012. C. 201-218.

18.Шмульская Л.С., Славкина И.А., Веккессер М.В., Мамаева С.В. Отражение территориальной идентичности в письменных работах школьников // Успехи современной науки. 2016. №9 (4). С. 67-69.

19. Юрченко В.С. Космический синтаксис: Бог, Человек, Слово. Лингво-философский очерк. Саратов: СГПИ, 1992. 136 с.

\section{References}

1. Anisimova A.A., Echevskaja O.G. Sibirskaja identichnost': predposylki formirovanija, konteksty aktualizacii: [Siberian identity: prerequisites for the formation, updating contexts]. Novosibirsk: NGU, 2012. $176 \mathrm{p}$.

2. Bahor T.A., Zyrjanova O.N., Lobareva V.S. Associativnye polja kak voploshhenie regional'noj samoidentifikacii [Associative fields as an embodiment of regional self-identification]. Innovacionnye tehnologii 
nauchnogo razvitija: sbornik statej mezhdunarodnoj nauchno-prakticheskoj konferencii [Innovative technologies of scientific development: a collection of articles of the international scientific-practical conference]. Ufa, 2016, pp. 83-84.

3. Vekkesser M.V., Mamaeva S.V., Slavkina I.A., Shmul'skaja L.S. Projavlenie regional'noj samoindetifikacii avtora v pojeticheskom diskurse [The manifestation of the author's regional self-identification in poetic discourse]. Sovremennye issledovanija social'nyh problem, no 27, 2016, pp. 120-134.

4. Gorelov I.N., Sedov K.F. Osnovy psiholingvistiki. [Fundamentals of psycholinguistics]. M. Labirint, 1998. P. 114.

5. Zyrjanova O.N., Bahor T.A., Lobareva V.S. Arhetipicheskaja osnova maloj prozy I. Panteleeva [The archetypal basis of small prose I. Panteleyev]. Fundamental'nye issledovanija, no 8-6, 2013, pp. 487490.

6. Karasik V.I. Aspekty jazykovoj lichnosti [Aspects of linguistic identity] Problemy rechevoj kommunikacii [Problems of speech communication]. Saratov, 2003, pp. 96-106.

7. Karasik V.I. Jazykovoj krug: lichnost', koncepty, diskurs [Language circle: personality, concepts, discourse]. M.: Gnozis, 2004. 390 p.

8. Karaulov Ju.N. Russkij jazyk i jazykovaja lichnost' [Russian language and linguistic personality]. M.: Nauka, 1987. 262 p.

9. Krasavskij N.L. Jemocional'nye koncepty v nemeckoj i russkoj lingvokul'turah [Emotional concepts in German and Russian linguocultures]. M.: Gnozis, 2008. 374 p.

10. Krasnyh V.V. Osnovy psiholingvistiki teorii kommunikacii: kurs lekcij. [Foundations of psycholinguistics and theory of communication: a course of lectures] M.: ITDGK «Ngozis», 2001. 270 p.

11. Krysin L.P. Sovremennyj russkij intelligent: shtrihi k rechevomu portretu [Modern Russian intellectual: touches to the portrait of a voice]. Literaturnyj jazyk i kul 'turnaja tradicija [Literary language and cultural tradition]. M.: RAN, Institut jazykoznanija, 1994. 274 p.

12. Mazurova N.A., Zyrjanova O.N., Bahor T.A. Dendrologicheskie obrazy kak forma projavlenija regional'noj identichnosti v tvorchestve po- 
jetov Krasnojarskogo kraja [Dendrological images as a form of manifestation of regional identity in the work of poets of the Krasnoyarsk Territory]. Sovremennye issledovanija social'nyh problem, no 3-2 (27), 2016, pp. 195-207.

13. Mamaeva S.V., Slavkina I.A., Shmul'skaja L.S., Vekkesser M.V. Sociolingvisticheskij portret shkol'nikov-podrostkov kak rechevoj marker regional'noj identichnosti [Sociolinguistic portrait of teenage schoolchildren as a speech marker of regional identity]. Uspehi sovremennoj nauki, no 9, tom 4, 2016, pp. 47-50.

14. Romanova T.V. Socio- i psiholingvisticheskie osnovanija dlja tipologicheskoj harakteristiki russkoj jazykovoj lichnosti [Socio- and psycholinguistic bases for typological features of the Russian linguistic identity]. Social'nye varianty jazyka: materialy mezhdunar.nauch.konf. (16-17 apr.2009 g.) [Social variants of the language: materials of international scientific research (16-17 April 2009)]. N. Novgorod, 2009, pp. 24-27.

15. Slavkina I.A., Shmul'skaja L.S., Mamaeva S.V., Vekkesser M.V. Verbal'nye markery regional'noj identichnosti (na materiale sovremennyh chokonimov) [Verbal markers of regional identity (on the basis of modern choconims)]. Sovremennye issledovanija social'nyh problem, no. 3-2 (27), 2016, pp. 227-243.

16. Tarasenko T.P. Jazykovaja lichnost'starsheklassnika v aspekte ee realizacii [The language person of the senior pupil in aspect of its implementation]. Krasnodar, 2007. 25 p.

17. Fel'de O.V. Obraz Ameriki v jazykovom soznanii zhitelej Srednej Sibiri (po dannym psiholingvisticheskogo jeksperimenta) [The image of America in the linguistic consciousness of the inhabitants of Central Siberia (according psycholinguistic experiment)]. NOMO COMMUNICANS: Chelovek $v$ prostranstve mezhkul'turnyh kommunikacij [NOMO COMMUNICANS: Man in the space of intercultural communications]. Pod red. Kristiny Janashek, Jolanty Miturska-Bojanovskoj. Shhecin: GRAFFORM. 2012, pp. 201-218.

18. Shmul'skaja L.S., Slavkina I.A., Vekkesser M.V., Mamaeva S.V. Otrazhenie territorial'noj identichnosti v pis'mennyh rabotah shkol'nikov [Re- 
flection of territorial identity in written works of schoolchildren]. Uspehi sovremennoj nauki, no 9, V. 4, 2016, pp. 67-69.

19. Jurchenko V.S. Kosmicheskij sintaksis: Bog, Chelovek, Slovo. Lingvo-filosofskij ocherk [Space syntax: God, Man, the Word. Linguo-philosophical essay]. Saratov: SGPI, 1993. 136 p.

\section{ДАННЫЕ ОБ АВТОРАХ}

Славкина Инга Анатольевна, кандидат филологических наук, доцент, доцент кафедры русского языка и литературы Лесосибирский педагогический институт - филиал Сибирского федерального университета ул. Победы, 42, г. Лесосибирск, Красноярский край, 662543, Российская Федерация ingaslavkina@yandex.ru

Шмульская Лариса Степановна, кандидат филологических наук, доцент, доцент кафедры русского языка и литературы Лесосибирский педагогический институт - филиал Сибирского федерального университета ул. Победы, 42, г. Лесосибирск, Красноярский край, 662543, Российская Федерация lara_sh1973@rambler.ru

Мамаева Светлана Викторовна, кандидат филологических наук, доцент, доцент кафедры русского языка и литературы Лесосибирский педагогический институт - филиал Сибирского федерального университета ул. Победь, 42, г. Лесосибирск, Красноярский край, 662543, Российская Федераичия svmamaeva@mail.ru

Веккессер Мария Викторовна, кандидат филологических наук, доцент, доцент кафедры русского языка и литературы Лесосибирский педагогический институт - филиал Сибирского федерального университета 
ул. Победы, 42, г. Лесосибирск, Красноярский край, 662543, Российская Федерачия vekkesser2012@yandex.ru

\section{DATA ABOUT THE AUTHORS}

Slavkina Inga Anatol'evna, Ph.D.in Philology, Associate Professor at the Department of Russian Language and Literature Lesosibirsk Pedagogical University - affiliated branch of Siberian Federal University

42, Pobedy Str., Lesosibirsk, Krasnoyarsky kray, 662544, Russian Federation ingaslavkina@yandex.ru

Shmul'skaya Larisa Stepanovna, Ph.D.in Philology, Associate Professor at the Department of Russian Language and Literature Lesosibirsk Pedagogical University - affiliated branch of Siberian Federal University

42, Pobedy Str., Lesosibirsk, Krasnoyarsky kray, 662544, Russian Federation lara_sh1973@rambler.ru

Mamaeva Svetlana Victorovna, Ph.D.in Philology, Associate Professor at the Department of Russian Language and Literature Lesosibirsk Pedagogical University - affiliated branch of Siberian Federal University

42, Pobedy Str., Lesosibirsk, Krasnoyarsky kray, 662544, Russian Federation svmamaeva@mail.ru

Vekkesser Mariya Victorovna, Ph.D.in Philology, Associate Professor at the Department of Russian Language and Literature Lesosibirsk Pedagogical University - affiliated branch of Siberian Federal University 42, Pobedy Str., Lesosibirsk, Krasnoyarsky kray, 662544, Russian Federation vekkesser2012@yandex.ru 